\title{
RSP Revisitada A face oculta do Leviatã: gestão da informação e transparência administrativa
}

Texto publicado na RSP de jan/abr de 1995 (vol. 119, ano 46, n.1)

José Maria Jardim

As reflexões sobre a transparência do Estado no Brasil encontram espaço particularmente nos anos oitenta, no bojo da conjuntura política referente aos projetos de democratização do país. No marco de tais reflexões, o direito à informação e o direito à privacidade face à ação do Estado passam a freqüentar assiduamente o discurso político. Tais análises não se expressam ainda em tentativas de formulação de políticas públicas na área de informação durante o mesmo período.

Como ente informativo, o Estado moderno configura-se como uma das maiores e mais importantes fontes de informação, além de requisitar uma grande quantidade destas para a sua atuação. Seu funcionamento relaciona-se diretamente com a sua própria ação produtora, receptora, ordenadora e disseminadora de informações. $\mathrm{O}$ objeto de tais ações seria, em última instância, o cidadão que, ao exercer o acesso à informação governamental, constitui-se como sujeito informativo. Isto é particularmente significativo ao se considerar as diferentes 
formas de intervenção do Estado na vida social. Do ponto de vista do direito à informação, deveria o Estado comunicar suas atividades e o impacto que estas produzem na sociedade à qual, por sua vez, teria assegurado, por princípio, o livre acesso a tais informações.

O grau de democratização do Estado encontra, neste aspecto, um dos seus pressupostos balizadores: quanto maior o acesso à informação governamental, mais democráticas as relações entre Estado e sociedade. A visibilidade social do Estado representaria assim um processo de dimensões políticas, técnicas, tecnológicas e culturais, tendo como um dos seus principais produtos a informação publicizada.

\section{Transparência administrativa}

A noção de transparência administrativa oferece diversas leituras. Tomada como um dos requisitos de controle da sociedade sobre o Estado, este termo encontra lugar em diversos discursos dos atores envolvidos na zona de tensão que decorre das relações entre Estado e sociedade. Esperase, ao longo deste artigo, identificar alguns indicadores que caracterizam a transparência administrativa como manifestação do Estado e demanda social.

Embora alguns admitam que a administração pública deva atuar imparcialmente, verifica-se que a sua organização a torna facilmente permeável à interferência de atores sociais os mais diversos. Reside aí o problema da separação das esferas políticas e administrativas, considerandose que o leque de questões sociais torna a administração pública moderna incompatível com a noção de neutralidade. A eficiência administrativa já não consistiria na aplicação rígida e imparcial das ordens por parte do burocrata, mas na sua receptividade aos fins sociais e políticos do sistema. "Num regime pluralista isto implica uma maior flexibilidade da ação administrativa e uma mais larga disponibilidade da burocracia para a contratação e o compromisso com os diversos grupos sociais" (SouzA, 1991, p. 20).

A participação social na formulação de políticas públicas constituiria, neste sentido, um processo inerente à transparência informacional do Estado. O chamado planejamento participativo com caráter de emancipação social regula e é regulado pelo acesso do cidadão à informação governamental. É o caso dos fluxos orçamentários públicos que, camuflados sob a capa confidencial ou secreta, constituem uma caixa-preta para a sociedade. Por outro lado, o fenômeno da politização do social, resultante de transformações tecnológicas, econômicas e sociais significa uma demarcação mais tênue entre Estado e sociedade em função da privatização da esfera pública e politização da esfera do privado. Conforme Bobbio (1990, p.74) o "Estado Social" é entendido "não só no sentido de Estado que permeou a sociedade mas também no sentido de Estado permeado pela sociedade". O Estado moderno responderá a essas mudanças com a criação de normas, regulamentos e contratos que levam ao crescimento da burocracia em uma escala à qual nem sempre corresponde o grau de sua transparência administrativa.

\section{As racionalidades}

Tais questões entrecruzam-se com outras, sugeridas pelas discussões em torno da racionalidade.

A desvinculação entre a práxis e a concepção teórica clássica da razão fornecerá a base para a racionalidade 
característica da sociedade capitalista: a razão formal ou funcional, que assegura para a organização burocrática, conforme Weber, a "calculabilidade precisa dos fatores técnicos" e a "completa previsibilidade de funcionamento". Trata-se da razão que considera o homem mero calculador utilitário de conseqüências. Racionalidade formal que, conforme Marcuse, é anticrítica e anti-histórica, resultante de um projeto histórico de dominação.
- a falência desse tipo de racionalidade para informar a construção de uma realidade humana qualitativamente diferenciada;

- a impossibilidade de definição de um quadro substantivo de referência normativa da vida humana,formulado exclusivamente a partir da racionalidade formal.

A racionalidade formal estaria contraposta à racionalidade substantiva e à dialética. Estas duas expressões de racionalidade teriam como característica

Um dos pressupostos do Estado moderno é a sua visibilidade social mediante a implementação de instrumentos gerenciais de controle das informações que produz é o seu acesso pelo cidadão. A gestão da informação configura-se como um conjunto de práticas caracterizadas pela racionalidade formal e o projeto histórico do Estado contemporâneo. No Brasil e demais países da América Latina, a opacidade informacional do Estado expressa uma situação em que este não dispõe de mecanismos de controle sobre seus estoques informacionais. Por outro lado e, em conseqüência, a sociedade não controla o Estado. $\boldsymbol{O}$ tema requer a construção de referenciais analíticos, além do confronto das diversas experiências históricas envolvendo as relações entre gestão da informação e a transparência administrativa.

Mostrando-nos que Weber foi interpretado por Marcuse de forma relativamente equivocada, Habermas (1983) questiona a ditadura da racionalidade formal ao apontar a possibilidade de interação entre o agir racional com respeito a fins e o agir comunicativo, entre o imperativo do trabalho e o da interação simbólica.

Tanto Marcuse quanto Habermas indicam-nos três aspectos básicos sistematizados por Medeiros e Brandão (1990):

- o reconhecimento dos limites da racionalidade formal, dada a sua predominância no desenho moderno da sociedade; comum a possibilidade de informar projetos de transformação qualitativa da realidade humana: o indivíduo, enquanto ator político, ancorado numa racionalidade múltipla e indeterminada delibera politicamente sobre a sua realidade.

\section{Burocracia e informação}

Sob a perspectiva weberiana, a organização burocrática é caracterizada

"por relações de autoridade entre posições ordenadas sistematicamente de modo hierárquico, por esferas de 
competência claramente distintas, por uma elevada divisão de trabalho e uma precisa separação entre pessoa e cargo, no sentido de que os funcionários e os empregados não possuem, a título pessoal, os recursos administrativos, dos quais devem prestar contas, e não podem apoderar-se do cargo." (Weber, 1979, p. 247).

A burocracia constitui-se, assim, em um tipo de poder, confundindo-se com a própria organização, ou seja, "é um sistema racional em que a divisão do trabalho se dá racionalmente com vistas a fins. A ação racional burocrática é a coerência da relação de meios e fins" (ibid., p. 235). Reconhecendo a burocracia como uma função necessária em uma sociedade de massas, Weber (ibid.) questiona, porém, o seu domínio absoluto sobre a sociedade. Neste sentido, a ação da burocracia seria racional quando limitada à sua própria esfera, tornando-se irracional quando atinge outras esferas.

Ao definir a burocracia como a estrutura administrativa de que se serve o tipo mais puro de domínio legal, Weber ressalta ainda que as funções administrativas da organização burocrática são exercidas de modo continuado com base em documentos escritos.

A administração de um cargo moderno se baseia em documentos escritos ('os arquivos') preservados em sua forma original ou em esboço. $\mathrm{O}$ quadro de funcionários que ocupe um cargo 'público', juntamente com os seus arquivos de documentos e expedientes, constitui uma 'repartição' (WEBER, 1982, p. 230).

Efetivamente, algumas das características mais comuns na administração pública como função e organização formalmente estabelecidas são a geração, o processamento técnico e a consulta a informações registradas em um suporte material, decorrentes de suas atividades. Neste sentido, os serviços de gerenciamento da informação arquivística representariam um aspecto institucionalizante da administração pública. Por outro lado, os documentos arquivísticos por esta produzidos constituiriam uma linguagem que lhe é própria e indispensável à sua sobrevivência e operações. Dois fenômenos sinalizam, segundo Ampudia Mello (1988, p. 12-13, tradução nossa), os processos informacionais arquivísticos dentro das administrações públicas:

"o primeiro pode denominar-se objetivação e consiste em que a informação institucional se assenta sempre sobre um suporte material...; ao segundo fenômeno pode chamar-se formalização e consiste em que dentro das instituições a informação circula através de canais previa e claramente estabelecidos, integrando redes que unem hierarquicamente a todas e cada uma das partes que as compões. (...) tal informação objetivada são os documentos e arquivos que durante tantos séculos a Administração Pública tem se empenhado em produzir, assim como os canais formais de informação são os sistemas internos que esta criou para gerar, distribuir e conservar seus registros".

A informação arquivística produzida pela administração pública cumpre teoricamente um ciclo que envolve a sua produção, processamento, uso e estocagem em dois contextos necessariamente interativos: primeiramente no ambiente organizacional da 
sua produção e, em um segundo momento, no marco das instituiçoes arquivísticas responsáveis pela normalização da gestão de documentos da administração pública, bem como pela preservação e acesso ao patrimônio documental arquivístico produzido pelo Estado.

No primeiro cenário, a informação arquivística encontra-se relacionada às solicitações do processo decisório governamental (arquivos correntes). À medida que esta informação torna-se menos utilizada ao longo do processo decisório, tende-se a eliminá-la ou a conservá-la temporariamente (arquivos intermediários gerenciados pela própria administração produtora ou pelas instituições arquivísticas). Para tal, consideram-se as possibilidades de uso eventual da informação pelo organismo produtor ou a sua condição de documento de valor permanente. À esta configuração chegariam, segundo a Unesco, 10\% dos documentos produzidos (arquivos permanentes). Constituindo os arquivos permanentes, estes documentos têm sua guarda e acesso pelas instituições arquivísticas justificados pelo seu uso para a pesquisa científica ou como fator de testemunho das ações do Estado e garantia de direitos dos cidadãos.

As possibilidades de acesso à informação governamental pelo administrador público e pelo cidadão encontram-se, portanto, diretamente relacionadas com o conjunto de práticas desenvolvidas pela administração pública no decorrer desse ciclo informacional.

\section{A gestão da informação governamental}

A perspectiva de políticas arquivísticas contemplarem todo o ciclo da informação ganha contornos teóricos e desdobramentos práticos com a concepção de gestão de documentos, particularmente nas administrações públicas dos Estados Unidos e Canadá após os anos 50.

De acordo com o Dicionário de Terminologia Arquivística do Conselho Nacional de Arquivos (1988, p. 104), “a gestão de documentos diz respeito a uma área da administração geral relacionada com a busca de economia e eficácia na sua produção, uso e destinação final". Com a implementação da gestão de documentos, as instituições arquivísticas norte-americanas passam a assumir as características de organizações responsáveis não apenas pela guarda e acesso de documentos de valor permanente, mas por todo o ciclo vital da informação arquivística, incluindo as sua fases corrente e intermediária.

Paralelamente, a idéia de era $d a$ informação é ressaltada pela emergência de novas tecnologias da informação. Estas tecnologias, socialmente difundidas e crescentemente utilizadas nas administrações públicas, produzem novos paradigmas de organização, processo decisório, poder central e local e acesso à informação pelo cidadão.

Apesar dos benefícios gerados pela gestão de documentos, o governo dos Estados Unidos criou, na metade dos anos setenta, a Comissão Federal sobre Fluxo de Papéis em função dos problemas apresentados pelos departamentos e agências do governo. Como alternativa à situação diagnosticada, a Comissão sugeriu a adoção da Gestão de Recursos Informacionais (GRI), então definida como:

"o planejamento, gerenciamento, previsão orçamentária, organização, direcionamento, treinamento e controle associados com a informação governamental. O termo abrange 
tanto a informação propriamente dita, quanto recursos relacionados, tais como pessoal, recursos financeiros e tecnologia” (Cronin, 1990, p.45).

Emergem a partir dos anos 80 as práticas de G.R.I., trazendo implicações conceituais e operacionais para a gestão de documentos e a sua inserção nos sistemas de informação governamental. Pode-se afirmar, portanto, que a gestão de documentos e a gestão de recursos informacionais constituem campos do conhecimento e conjuntos de práticas operacionais - aqui designadas como gestão da informação - intrinsecamente relacionadas com a racionalidade formal e o projeto histórico do Estado contemporâneo. Como experiências históricas, encontram-se mais freqüentemente reconhecidas no âmbito do Estado democrático das chamadas sociedades pós-industriais.

\section{Informação, segredo e transparência}

Weber ressalta "os meios especificamente modernos de comunicações como fundamentais para o Estado moderno" (ibid., p. 250), fornecendo, neste sentido, as bases para as análises posteriores sobre a informação no processo decisório no âmbito das burocracias. Esta perspectiva toca, inclusive, a discussão sobre o grau de transparência informacional do Estado ao afirmar que "toda burocracia busca aumentar a superioridade dos que são profissionalmente informados, mantendo secretos seus conhecimentos e intenções. O conceito de segredo oficial é invenção específica da burocracia e nada é tão fanaticamente definido pela burocracia quanto esta atitude" (ibid.; p.252).

Como observa Bobbio (ibid., p.87), o princípio da publicidade das ações de quem detém um poder público encontra uma referência histórica em Kant quando este considera como "fórmula transcendental do direito público" o princípio segundo o qual "todas as ações relativas ao direito de outros homens cuja máxima não é conciliável com a publicidade são injustas".

Se na monarquia de direito divino a invisibilidade do poder real é uma exigência, no Estado moderno o segredo é, por princípio, legitimado apenas nos casos excepcionais, legalmente previstos. No entanto, assinala Almino (1986, p. 106) "por mais amplas e abertas que sejam ou venham a ser as discussões no interior do Estado e por mais que estas possam refletir o que ocorre na sociedade, uma certa desconfiança mútua, inerente ao processo decisório hierarquizado e à visão do Estado como concentrador do poder, faz com que erija uma barreira entre Estado e sociedade no plano da informação".

O segredo impediria um controle mais efetivo por parte da sociedade sobre seus governantes, constituindo uma forma de evitar o julgamento, preservando, assim, o lugar do poder. "Cria-se uma realidade escondida e outra aparente. Tendo acesso apenas a esta última, a sociedade é mantida na ignorância de processos decisórios que lhe dizem respeito" (ibid.). Bobbio (1990, p. 97) aponta também para os limites da transparência ao afirmar que "a vitória do poder visível sobre o poder invisível jamais se completa: o poder invisível resiste aos avanços do poder visível, inventando sempre novos modos de se esconder, de ver sem ser visto".

Um outro aspecto, portanto, que permeia tal discussão é o conceito de controle. Sob a perspectiva das teorias administrativas, produtos da racionalidade formal, a razão de ser do controle é 
garantir a concretização de expectativas com respeito a acontecimentos futuros. Conforme Hamptom apud Martins (1989, p. 83) "controlar significa obter informações sobre o desempenho e com elas realimentar os tomadores de decisões de forma que possam comparar os resultados reais com os planejados e decidir o que fazer com respeito às discrepâncias observadas". Assim, o excesso de controle poderia significar perda de autonomia e comportamentos disfuncionais. Reconhecendo as conotações negativas que a idéia de controle envolve, Martins (1989, p.83) ressalta que democracia e controle não são termos antitéticos, sobretudo no que se refere aos mecanismos de controle do Estado sobre si mesmo e da sociedade sobre o Estado.

"Como afirmava Montesquieu, todo aquele que detém poder tende a abusar dele e assim procederá enquanto não encontrar limites. As instituições características da vida republicana foram criadas justamente para estabelecer esses limites e colocar à disposição do povo instrumentos adequados ao controle do poder político".

Um dos instrumentos mais recentes de controle do Estado pela sociedade é o direito à informação governamental. O princípio do direito à informação governamental achase legalmente expresso em países como a Finlândia (1951), Estados Unidos (1966), Dinamarca e Noruega (1970), França, Holanda e Espanha (1978), Austrália e Canadá (1982). No Brasil, o direito à informação governamental é garantido pela Constituição de 1988 e a Lei de Arquivos $^{1}$. Ainda não regulamentados estes mecanismos legais, o cidadão esbarra, porém, em outros obstáculos. Esta situação pode ser ilustrada com a pesquisa realizada por técnicos da Divisão de Pré-Arquivo do Arquivo Nacional em 1989, abrangendo 309 depósitos de documentos em 48 órgãos da administração federal direta nas cidades do Rio de janeiro e em Brasília. Os resultados indicaram a existência de 106.405 metros lineares nestes órgãos, do período de 1754 a 1989, sendo 62.206 metros lineares no Rio de Janeiro e 44.109 em Brasília. Apenas 11\% dos órgãos possibilitavam o acesso público às informações sob sua guarda. Atualmente o Arquivo Nacional armazena cerca de 26 quilômetros no Rio de Janeiro e 14 quilômetros em Brasília, dos quais grande parte ainda inacessíveis ao cidadão. Esta situação, detectada no plano federal e ainda persistente, tende a se reproduzir, em menor escala, nos planos estadual e municipal. Observa-se, portanto, que o ciclo da informação arquivística na administração pública brasileira encontra-se profundamente comprometido.

Nesse quadro, os estoques informacionais dos arquivos públicos tendem a ser considerados como parte de uma memória coletiva tomada como produto e não como processo. Esta memória arqueologizável é frequentemente identificada sob a noção de patrimônio documental arquivístico. Os arquivos públicos, via de regra, promovem a monumentalização ${ }^{2}$ dos documentos que compõem seus acervos mediante ações que favorecem a recuperação e a divulgação de determinadas informações em detrimento de outras. É o caso, por exemplo, da elaboração de detalhados instrumentos de recuperação de informações sobre um pequeno segmento do acervo em detrimento de um controle intelectual mais global sobre o conjunto dos fundos documentais. Além disso, tais instrumentos 
apresentam-se com freqüência pouco amigáveis ao usuário da informação, seja este o pesquisador científico ou o cidadão comum na busca pela comprovação dos seus direitos.

Os acervos dos arquivos públicos sinalizam, portanto, um processo de constituição de um patrimônio documental que resulta e, em alguns casos, ressalta a opacidade informacional do Estado. Por outro lado, privilegiam a sua transparência informacional mediante escassos conjuntos documentais que, monumentalizados, são disponibilizados para o cidadão. E o fazem sob a perspectiva de exercitarem uma função pública tomada como neutra a partir de práticas informacionais que tendem a ser consideradas não menos neutras por um dos seus principais agentes: o profissional da informação ${ }^{3}$.

\section{Informação e Estado na América Latina}

Na América Latina, a precariedade organizacional dos arquivos públicos e o uso social incipiente da informação governamental expressam a trajetória de suas administrações públicas bem como suas condições políticas, econômicas e sociais. Os arquivos públicos latino-americanos institucionalizaram-se como resultado de um processo de independência que levou à formação dos Estados modernos na região. Foram considerados arquivos históricos, repositórios de uma memória tida como forjadora da identidade nacional emergente. Isto implicou desenvolvimento de arquivos públicos e serviços arquivísticos periferizados na administração pública, incapazes de fornecer informações suficientes para a pesquisa científica e tecnológica e à sociedade como um todo.

De maneira geral, as instituições arquivísticas públicas latino- americanas apresentam características comuns no que se refere à sua atuação. Tratam-se de organizações voltadas quase exclusivamente para a guarda e acesso de documentos considerados, se parâmetros científicos, como de valor histórico, ignorando a gestão de documentos. Estes, por sua vez, tendem a ser acumulados sem critérios junto aos serviços arquivísticos da administração pública, dada a inexistência de programas de avaliação, eliminação e recolhimento de documentos aos arquivos públicos. Seja nestas instituições ou nos demais setores da administração pública, a ausência de padrões de gerenciamento da informação, somada às limitações de recursos humanos, materiais e tecnológicos, resulta em deficiências no processamento técnico. Ao não desenvolverem a interação inerente ao controle do ciclo da informação arquivística, tanto os arquivos públicos como os demais serviços arquivísticos da administração pública desvinculam-se do processo políticodecisório governamental. Por outro lado, as restrições de consulta e as condições de acesso físico e intelectual dos arquivos limitam consideravelmente sua utilização pelo administrador público e o cidadão.

Conforme Ampudia Mello (1988, p. 39, tradução nossa),

"A dispersão e a debilidade das estruturas arquivísticas resultam sintomáticas da feudalização da administração pública, dividida em núcleos de influência e poder que, em grande parte, se baseiam no controle privado da informação governamental; por outro lado, sob a heterogeneidade e improvisação das técnicas arquivísticas, pode-se destacar a subordinação das funções públicas a interesses subjetivos daqueles que as exercem, que determinam, segundo sua conveniência, 
como devem integrar-se os registros de sua gestão: por sua vez, a marginalização e menosprezo das áreas arquivísticas, consideradas receptáculo natural de tudo que é inútil, resultam ilustrativos do próprio descrédito do sentimento institucional da atividade governamental... em outro extremo, a falta de controle sobre os documentos oficiais que freqüentemente são objeto de apropriação por parte dos funcionários governamentais, constitui um reflexo fiel da tendência a desvirtuar o caráter público da administração, de cujo patrimônio os arquivos são parte fundamental".

A transparência informacional do Estado, expressa no discurso da lei, é superada pela opacidade informacional da administração pública, fenômeno historicamente associado ao projeto de Estado sustentado no Brasil e demais países latino-americanos. Tal projeto tem favorecido um Estado que sistematicamente negligencia os interesses das sociedades às quais caberia servir. No caso brasileiro, trata-se de um Estado marcado pela centralização e pelo autoritarismo, acolhendo nichos de modernização sem ser completamente moderno, nem autenticamente republicano, coexistindo em seu interior diferentes princípios de estruturação - o patrimonial e o burocrático. Nesse quadro, configura-se uma situação em que:

- E Estado não controla a si mesmo, o que se expressa na fragilidade da maior parte de suas estruturas e recursos informacionais e na ausência de políticas de informação;

- por outro lado e, em conseqüência, a sociedade não controla o Estado, dadas as escassas possibilidades de acesso à informação governamental.

\section{Inconclusões}

Como pudemos verificar, os laços que vinculam a gestão da informação governamental à transparência administrativa permitem diversas abordagens. Os olhares sobre o tema envolvem desde aspectos teóricos-operacionais até a construção de quadros referenciais teóricos que ampliem os limites das análises mais freqüentes. Nesse sentido, a literatura a respeito mostra-se ainda incipiente, privilegiando uma perspectiva muitas vezes tecnicista. A busca por novos parâmetros de análise pressupõe um esforço de investigação interdisciplinar que ilumine novos caminhos nos planos teóricos e empíricos.

Uma das alternativas possíveis envolve a questão da racionalidade, compreendida em sua multiplicidade conceitual, de modo a favorecer a construção de referenciais analíticos. Por outro lado, ao reconhecerse que a gestão da informação não constitui um campo de saber e um conjunto de operações dotadas de neutralidade, sugerese a sua problematização enquanto processos não apenas técnicos ou tecnológicos mas também políticos.

A transparência administrativa do Estado merece ser incluída como objeto dessas possibilidades de análise, sobretudo ao confrontarmos suas relações com a teoria e práticas de gestão da informação em experiências históricas diversas. Tais experiências mostram, como no caso dos Estados autoritários, que o controle da produção, uso e destinação da informação registrada não leva como conseqüência imediata à transparência administrativa. Mesmo nos Estados democráticos, em que medida a transparência administrativa é capaz de relativizar os domínios da burocracia estatal sobre a sociedade? 
Mas, afinal, o que vem a ser esta transparência informacional à qual se atribui um valor de mediação entre Estado e sociedade? Um discurso instituído a partir da burocratização não só do Estado como da sociedade contemporâneos? Uma espécie de saber instituinte capaz de favorecer a emancipação social? Produto de uma racionalidade instrumental, como a gestão da informação seria reguladora e regulada por uma ação emancipatória de transparência informacional? Consideradas as diversas respostas, que tais questões podem vir a oferecer, a transparência informacional é entendida aqui como um território para o qual confluem práticas informacionais do Estado e da sociedade. Território, por sua vez, construído e demarcado por essas mesmas práticas. A opacidade informacional do Estado sinaliza, ao contrário, um hiato entre este e a sociedade, configurando-se como processo e produto das características de geração e uso da informação pelo cidadão. Tratase, como tal, de uma arena de tensão e distensão ordenada na base do conflito e do jogo democrático. Qualquer projeto de reforma do Estado inclui, portanto, esta problemática na sua pauta de prioridades.

Face a estas questões, como visualizar a gestão da informação em suas dimensões teóricas e operacionais? Indagações desse teor merecem ser investigadas, considerando distintas experiências da gestão da informação como possíveis expressões do Estado social e democrático em sociedades de capitalismo avançado e as experiências em curso em países de terceiro mundo. Nesse momento, porém, o próprio conceito de gestão da informação encontra-se em constante confronto com as demandas impostas pelas novas tecnologias à produção e circulação da informação no âmbito do estado e seu uso social.

Nesse quadro, a organização, o registro da informação e o próprio processo decisório governamental vêm-se alterando em função da vertiginosa informatização do Estado e da sociedade. Nunca terão ido tão longe as possibilidades de visibilidade e também de invisibilidade do Estado. Mais uma vez colocam-se os desafios para assegurar a sociedade como garantia do Estado, e não o contrário.

\section{Notas}

1 Ver Lei 8.159 de 9 de janeiro de 1991, que dispõe sobre a política nacional de arquivos públicos e privados e dá outras providências.

2 Nos termos sugeridos por LE GOFF (1984) o documento monumentalizado tem por características uma intencionalidade em evocar o passado.

3 Considera-se, neste artigo, como profissional da informação aquele que atua em uma ou mais etapas do ciclo da informação arquivística, em seus diferentes níveis de gerenciamento, seja arquivista ou não. 


\section{Referências bibliográficas}

Almino, João. O segredo e a informação: ética e cidadania no espaço público. São Paulo: Brasiliense, 1986.

Ampudia Mello, I. Enrique. Institucionalidad y Gobierno: un ensayo sobre la dimensión archivística de la administración pública. México: Archivo General de la Nación, 1988. Arquivo Nacional. Cadastro Nacional de Arquivos Federais. Brasília: Presidência da República, 1990.

Bearman, David. Diplomatic, weberian bureaucracy and the management of eletronic records. The American Archivist. Chicago, v.55, n.1, winter 1972.

Bobbio, Norberto. Estado. governo, sociedade: para uma teoria geral da política. Rio de Janeiro: Paz e Terra, 1990.

Cronin, Blaise. Esquemas conceituais e estratégicos para a gerência da informação. Revista da Escola de Biblioteconomia da UFMG. Belo Horizonte, v.19, n.2, set.1990.

Demo, Pedro. Participação e planejamento. Revista de Administração Pública. Rio de Janeiro, v. 25, n.3, jul./set. 1991.

Habermas, Jurgen et allii. Textos escolhidos. São Paulo: Abril Cultural,1983.

Jardim, José Maria. O conceito e a prática de gestão de documentos. Acervo. v. 3, n.3, dez. 1987.

Jardim, José Maria. Relatório sobre a situação dos Arquivos Públicos na Argentina, Chile e Uruguai.

Rio de Janeiro: Arquivo Nacional, Associação Latino-Americana de Arquivos, Conselho Internacional de Arquivos, 1987.

International Council on Archives. Dictionarv of Archival Terminology. Munchen, NewYork, London, Paris: Saur, 1988.

LE Goff, Jacques. Memória/ História. Enciclopédia Einaudi. Porto: Imprensa Nacional Casa da Moeda, 1984.

Machado, Maria Helena. A sociedade e as organizações. Revista de Administracão Pública. Rio de Janeiro, v.23, n.1, jan./mar. 1989.

Marcuse, Herbert. Sobre Max Weber. In.: Weber, Max. O politico e o cientista. Lisboa: Editorial Presença, s.d.

Martins, Carlos Estevam. Governabilidades e controles. Revista de Administração Pública. Rio de Janeiro, v.23, n.1, p. 5-20, jan./mar. 1989

Medeiros, Antonio Carlos, Brandão, Hugo Júnior. Em busca de novos paradigmas para a análise de políticas públicas. Revista de Administração Pública. Rio de Janeiro, v. 24, n. 3, p. 4-53, maio/jul. 1990.

Souza, Celina. A crise do Estado e do seu aparelho. Revista de Administração Pública. Rio de Janeiro, v. 25, n. 3, jul./set. 1991.

Weber, Max. Ensaios de sociologia. Rio de Janeiro: Guanabara, 1979. 


\section{Resumo-Resumen-Abstract}

\section{A face oculta do Leviatã: gestão da informação e transparência administrativa José Maria Jardim}

Um dos pressupostos do Estado moderno é a visibilidade social mediante a implementação de instrumentos gerenciais de controle das informações e o acesso a estas por parte do cidadão. A gestão da informação configura um conjunto de práticas caracterizadas pela racionalidade formal e pelo projeto histórico do Estado contemporâneo. No Brasil e no restante da América Latina, a falta de transparência mostra uma situação em que o Estado não dispõe de mecanismos de controle sobre as reservas de informação; por outro lado e, em conseqüência, a sociedade não controla o Estado.

O tema requer a construção de referenciais analíticos, além do confronto das diversas experiências históricas e das relações entre a gestão da informação e a transparência administrativa.

\section{La faz oculta de Leviatan: gestión de información y transparencia administrativa JoséMaria Jardim}

Uno de los supuestos del Estado moderno es su visibilidad social mediante la implementación de instrumentos gerenciales de control de las informaciones y el acceso a las mismas, por parte el ciudadano. La gestión de la información se configura como um conjunto de prácticas caracterizadas por su racionalidad formal y el proyecto histórico del Estado contemporâneo. En Brasil y en el resto de latinoamérica, la falta de transparência del Estado expresa uma situación en que este no dispone de mecanismos de control sobre sus stocks de información. Por outro lado, y en consecuencia, la sociedad no controla al Estado.

El tema requiere la construcción de referenciales analíticos, además del confronto de las diversas experiencias históricas y las relaciones entre la gestión de la información con la transparencia administrativa.

\section{The hidden face of Leviathan: information management and administrative transparency JoséMaria Jardim}

One of the assumptions of the modern state is its social transparency through the implementation of management tools for the control of the information it produces, as well as its access by the citizen. Information management is a set of practices characterized by formal rationality and the historical Project of the contemporary state. In Brazil, as well as in other Latin-American countries, the lack of state information transparency expresses a situation in which the state does not have mechanisms to control its information stocks. On the other hand, and as a result, society does not control the state. The subject requires the construction of analytical frames of reference, as well as the comparison of various historical experiences involving the relationships between information management and administrative transparency.

José Maria Jardim

Professor do Departamento de Documentação da Universidade Federal Fluminense. Contato: jardim@gmail.com 